\title{
Factors that influence peritonitis events on patients with continuous ambulatory peritoneal dialysis in Sanglah General Hospital, Denpasar-Bali, Indonesia
}

\author{
Gede Wirya Kusuma Duarsa' \\ Oka Udrayana ${ }^{2}$ \\ Yeni Kandarini ${ }^{3}$ \\ Raka Widiana $^{3}$ \\ Marleen ${ }^{4}$ \\ 'Department of Urology, Faculty of Medicine, \\ Udayana University/Sanglah General Hospital. \\ Denpasar, Bali. \\ ${ }^{2}$ Department of Surgery, General Hospital of \\ Buleleng, Buleleng, Bali \\ ${ }^{3}$ Division of Nephrology, Department of Internal \\ Medicine, Faculty of Medicine, Udayana \\ University/Sanglah Hospital, Denpasar, Indonesia \\ ${ }^{4}$ Neurosurgery Department, Faculty of Medicine, \\ Udayana University/Sanglah Hospital, Denpasar, \\ Indonesia
}

\begin{abstract}
Background. To determine risk factors that influence peritonitis event on patients with Continuous Ambulatory Peritoneal Dialysis (CAPD) in Sanglah Hospital, thus, we can prevent the occurrence of peritonitis in CRF patients with CAPD.

Methods. This is a retrospective cohort study, which was conducted at the Sanglah Hospital in Denpasar from August to September 2016. All data are processed using SPSS 17.0 for Windows, data analysis by using the Kaplan Meier (K-M) curves, hypothesis using the logrank test, while for the survival is by using the median or mean survival. The significance is determined by the value of $\mathrm{p}<0.05$ with $95 \%$ CI.

Results. A total of 78 people (46 men and 32 women) who meet the inclusion criteria of this study. Thirteen people (16.7\%) are experiencing peritonitis. K-M Survival Curves between in CRF patients with CAPD, with Age $\geq 50$ years (51.36 months survival rates, 95\% CI 44.79 until 57.93 ) with $<50$ years (56.1 months Survival rates, 95\% CI 51.41 until 60.78) with RR 2.54 log-rank p 0.084. K-M Survival Curves between in CRF patients with CAPD, with DM (mean 52.63 months survival rates, 95\% CI 47.21 until 58.06) with No DM (56.88 months survival rates, 95\% CI 52.89 until 60.88) with RR 4.16 and 0.037 log-rank p.

Conclusion. There is a correlation between DM and the incidence of peritonitis in CRF patients with CAPD at Sanglah Hospital. However, age and education level are not related.
\end{abstract}

Keywords: Peritonitis, age, education level, diabetes mellitus, CRF, CAPD

\section{Introduction}

Chronic Renal Failure (CRF) or end-stage renal disease (ESRD) is a clinical condition characterized by an irreversible decline in kidney function, to a degree that requires renal replacement therapy in the form of dialysis or kidney transplantation. In developing countries, the incidence is estimated at around $40-60$ cases per million population by the year. ${ }^{1}$

Since 1976, Popovich and his colleagues have introduced the use of Continuous Ambulatory Peritoneal Dialysis (CAPD) as a popular alternative therapy in patients with ESRD. ${ }^{2}$ 
Continuous Ambulatory Peritoneal Dialysis technique can lead to complications and mostly peritonitis. ${ }^{3}$ From the statistical data in the United States in 2000, noting that one incident in 12 to 24-months of peritoneal dialysis patients who had peritonitis. In a study conducted in Australia in which to evaluate the incidence of peritonitis for 12 months from February 2000 to January 2001, it was obtained that $64 \%$ $(145 / 293)$ of patients experienced peritonitis. ${ }^{4}$

In the preliminary research conducted by Haryati E, which discusses the most common microorganisms causing peritonitis in the year 2005-2009 in Denpasar Sanglah Hospital, it was obtained that peritonitis incidence over the past 5-years, the average annual/CRF patients living with CAPD therapy: 14\%, with the highest incidence was in 2007 and 2008. This study addressed the incidence of peritonitis as a complication of CAPD therapy in CRF, is still a problem that needs attention because of the high morbidity rate. ${ }^{5}$

The occurrence of peritonitis in patients with CAPD therapy is influenced by a number of risk factors such as age, race, socioeconomic status, educational level (intellect), immunocompromised status, nutritional status (hypoalbuminemia) and upper respiratory tract infections, 40 to $60 \%$ who have CAPD is Staphylococcus aureus carrier. Chronic Staphylococcus aureus carrier status is a risk factor for the development of chronic infection of the exit site and peritonitis. Besides the above risk factors, a factor which isn't less important in the occurrence of peritonitis is diabetes mellitus, tuberculosis, and secondary amyloidosis. ${ }^{5}$

There is controversy over the results of research in these countries, which also underpins the present study, whether the characteristics and risk factors of peritonitis in patients receiving CAPD therapy in Bali are similar or different according to the literature.

With all of the advantages of CAPD, it resulted that this technique becomes a popular choice for patients with CRF. However, considering the complication of peritonitis, which can aggravate morbidity and mortality of patients, it can affect doctors and patients thought to make this treatment option. By knowing the risk factors that influence the occurrence of peritonitis in CRF patients with CAPD therapy, it is expected that the incidence of peritonitis can be prevented.

\section{Method}

The present study is a retrospective cohort study. There were 78 people who met the inclusion and exclusion criteria for this study, which were conducted in Sanglah General Hospital in Denpasar from August to September 2016. The data were processed by using SPSS
17.0 for Windows and analyzed using K-M curves (Kaplan Meier), with the hypothesis test using log-rank, for survival using the median or mean survival. Significance is determined based on the value of $p<0.05$ with $95 \%$ CI.

\section{Results}

There were 78 people who met the inclusion and exclusion criteria for this study, consisted of 32 women (41\%) and 46 men (59\%) and 13 people from those 78 samples $(16.7 \%)$ experiencing peritonitis.

Table 1. Sample characteristics $(n=120)$

\begin{tabular}{|c|c|}
\hline Characteristics & $\mathbf{n}(\%)$ \\
\hline \multicolumn{2}{|l|}{ Age (y.o.) } \\
\hline $21-30$ & $7(9 \%)$ \\
\hline $31-40$ & $11(14 \%)$ \\
\hline $41-50$ & $29(37 \%)$ \\
\hline $51-60$ & $19(24 \%)$ \\
\hline $61-70$ & $8(10 \%)$ \\
\hline$>70$ & $4(6 \%)$ \\
\hline \multicolumn{2}{|l|}{ Sex } \\
\hline Male & $46(59 \%)$ \\
\hline Female & $32(41 \%)$ \\
\hline \multicolumn{2}{|l|}{ Race } \\
\hline Bali & $53(68 \%)$ \\
\hline Non-Bali & $25(32 \%)$ \\
\hline \multicolumn{2}{|l|}{ Education } \\
\hline Elementary & $33(42 \%)$ \\
\hline Middle & $16(21 \%)$ \\
\hline High & $23(29 \%)$ \\
\hline Bachelor & $6(8 \%)$ \\
\hline \multicolumn{2}{|l|}{ CAPD (month) } \\
\hline$<12$ & $19(24 \%)$ \\
\hline $12-24$ & $19(24 \%)$ \\
\hline $25-36$ & $8(11 \%)$ \\
\hline $37-48$ & $8(11 \%)$ \\
\hline $49-60$ & $10(12 \%)$ \\
\hline$>60$ & $14(18 \%)$ \\
\hline \multicolumn{2}{|l|}{$\mathrm{DM}$} \\
\hline Yes & $44(56 \%)$ \\
\hline No & $34(44 \%)$ \\
\hline
\end{tabular}


Table 2. Sample characteristics of patients with CRF therapy experiencing CAPD peritonitis based on research variables

\begin{tabular}{ccccc}
\hline \multirow{2}{*}{ Variable } & \multirow{2}{*}{ Category } & \multicolumn{2}{c}{ Peritonitis } & Total \\
& & Yes (\%) & No (\%) & \\
\hline Age (y.0.) & $\geq 50$ & $7(20 \%)$ & $28(80 \%)$ & 35 \\
& $<50$ & $6(14 \%)$ & $37(86 \%)$ & 43 \\
\multirow{2}{*}{ Education } & $<$ High school & $9(19 \%)$ & $39(81 \%)$ & 48 \\
& $\geq$ High school & $4(13 \%)$ & $26(87 \%)$ & 30 \\
\multirow{2}{*}{ DM } & Yes & $11(25 \%)$ & $33(75 \%)$ & 44 \\
& No & $2(6 \%)$ & $32(94 \%)$ & 34 \\
\hline
\end{tabular}

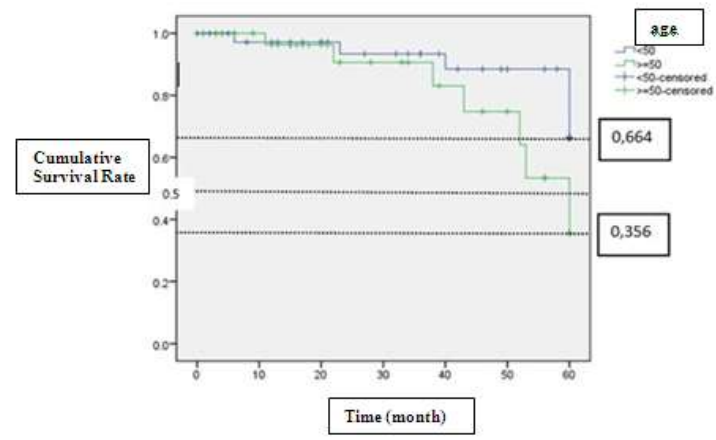

Figure 1. KM survival curves between patients with therapy CAPD GGK the aged $\geq 50$ years

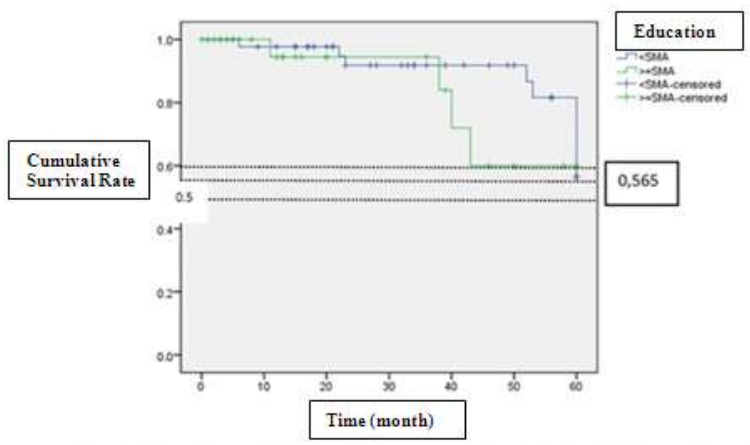

Figure 2. KM survival curves between patients with CRF with CAPD therapy education $\geq$ high school

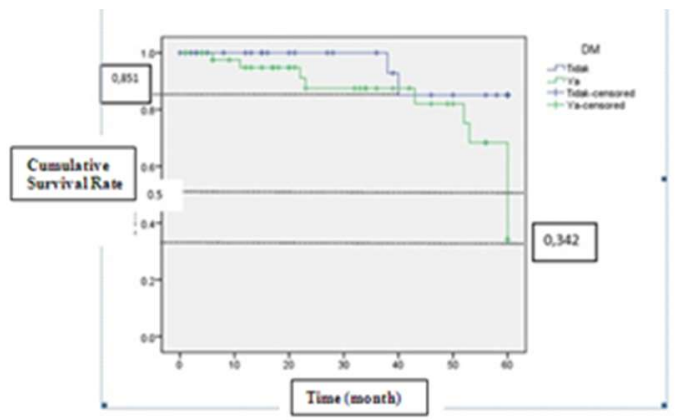

Figure 3. KM survival curves between $C R F$ patients with CAPD therapy with $D M$

\section{Discussion}

In the United States, Chronic renal failure in 1995-1999 was estimated 100 cases by the year, and this number increased by about $8 \%$ every year. In Malaysia, with a population of 18 million, there were an estimated 1800 new cases of kidney failure per year. In other developing countries, the incidence is estimated at around 40-60 cases per million population per year. ${ }^{1}$

In the Kaplan Meier (Figure 1) above, it can be concluded that the observation time up to 5 years, CRF patients receiving CAPD therapy with age $<50$ years have 0.664 probability to survive (no peritonitis) While CRF patients receiving CAPD therapy by age 50, the observation time up to 5 years, has 0.356 probability to survive (no peritonitis)

In clinical, probability of 0.356 for survival in patients with CRF with CAPD therapy influential age of $\geq 50$ years, given the probability of $<50 \%$ and this is also supported from the value of Relative Risk to age at 2.537. This means that the risk of peritonitis in patients with CRF receiving CAPD therapy, with the age of $\geq 50$ years at 2.537 times than the age of $<50$ years.

However, based on log-rank, it was obtained that the p-value of the age variable toward peritonitis was 0.084 . This indicated that differences in survival time between CRF patients with CAPD therapy for age greater than or equal to 50 years, compared with patients less than 50 years, did not statistically significant. This non-significant result was consistent with studies in Aracaju, Brazil, between January 2003 and December 2007, which stated that there was no significant difference between the peritonitis with a factor of gender, age, income level, and diabetes mellitus. ${ }^{6}$ In a study conducted Sharon $\mathrm{J}$ et al., (Canada) also supports research in Brazil that there was no significant difference between the incidence of peritonitis by age in patients with CAPD. ${ }^{7}$ Moreover in research conducted by Sirivongs $\mathrm{D}$ et al., (Thailand) explained that the patient peritonitis in CAPD it mostly occurs at age $<50$ years. ${ }^{8}$

This insignificant result might because of the sample size of CRF patients with CAPD therapy who had quite a little peritonitis. So if the sample added, it might get a meaningful result so that in line with studies that have been done by Gan HC et al., (Singapore), which states that, age and gender influence the occurrence of peritonitis in CAPD. ${ }^{9}$

In the above Kaplan Meier (Figure 2), it could be concluded that by the observation period up to 5 -years, CRF patients with CAPD therapy, with a high school education category, has a 0.6 probability to survive (no peritonitis). Whereas in CRF patients with CAPD therapy with category of education $<$ high school in which the observation time 
up to 5-years, has 0.565 probability to survive (no peritonitis).

The risk relative value for the educational level was 1.756. This meant that the risk of peritonitis in patients with CRF with CAPD therapy, with $\geq$ high school education level was 1.756 times than with education $<$ high school. Clinically, the value of 1.756 is quite significant since almost 2-times of CRF patients CAPD therapy with education $<$ high school. While by log-rank, it was obtained $0.340 \mathrm{p}$ value, it showed the difference between the survival time of CRF patients CAPD for education $\geq$ high school education, compared with patients $<$ high school was not statistically significant.

Theoretically, low levels of education can lead to a lack of understanding of the hygienic care CAPD, thus facilitate the infection. ${ }^{10,11}$ However, the results were not significant in this study was probably due to the way education officers of CAPD treatment toward patients were already good enough and or the level of caring of the patient in CAPD is hygiene, according to the officer who had been taught well enough.

This non-significant result was not in accordance with the study conducted by JVD Lobo et al., 2009 in Aracaju Brazil, mentioning that low educational risk factors associated with peritonitis. These results were probably due to the number of samples of CRF patients with CAPD therapy was quite small.

In Figure 3, the above Kaplan Meier can be concluded that the observation period for up to 5-years, CRF patients with DM who received CAPD therapy has a 0.342 probability to survive (no peritonitis). Whereas in CRF patients without DM with CAPD therapy, the observation time up to 5-years has the probability of 0.851 to survive (no peritonitis).

While with log-rank p-value, it was obtained $p 0.037$, it showed the difference between the survival time of patients with DM CRF receiving CAPD therapy compared with CRF patients without DM with CAPD therapy was statistically significant. This was consistent with the theory that DM will lead to complications, both microvascular and macrovascular, that caused the infection. Incidence of infections could cause serious complications for DM patients, as a result of decreasing the body's defenses. If the DM patient had an infection, the germs could multiply more rapidly. ${ }^{10,11}$

Additionally, the relative risk values for DM was 4.146. This meant that the risk of peritonitis in CRF patients with DM with CAPD therapy was 4.164 times than CRF patients without DM who received CAPD therapy. Clinically, 4.164 times the risk in patients suffering from DM for peritonitis is very influential. Similar results were obtained in a study conducted by Gan HC et al., (Singapore), which stated that in addition to diabetes, age, and gender influence the occurrence of peritonitis in CAPD. ${ }^{9}$ Similarly, studies that have been conducted by Sharma NK et al., (Nepal), which stated that the DM and Hipoalbumin as a powerful risk factor for the occurrence of peritonitis. ${ }^{12}$ Different results obtained in the study conducted by Lobo JVD et al., 2009 in Aracaju Brazil stated that there was no significant difference between peritonitis with diabetes mellitus.

\section{Conclusion}

There was a correlation between DM disease with the occurrence of the CRF peritonitis in patients with CAPD therapy at Sanglah Hospital in Denpasar, while age and education level were not related.

\section{References}

1. Suwitra, K. Penyakit ginjal kronik. In: Sudoyo AW et al., editors. Buku ajar ilmu penyakit dalam. 5th Ed. Jakarta: Internal Publishing; 2009:1035-104.

2. Javelosa R, Pena A, Javelosa G, et al. A clinical and microbiologic profile of peritonitis in chronic peritoneal dialysis at UERM memorial medical center: A retrospective study. Phil J Microbiol Infect Dis. 1988;17(1):34-6.

3. Poole Warren LA, Taylor PC, Farrel PC. Laboratory diagnosis of peritonitis in patients treated with continous ambulatory peritoneal dialysis. $J$ Pathology. 1989; 18(2): 237-9. DOI: $10.3109 / 00313028609059466$

4. Krediet RT. 30 Years of peritoneal dialysis development: The past and the future. Perit Dial Int. 2007;27 (Suppl 2):S35-41. DOI: 10.1177/089686080702702s06

5. Haryanti E, et al. Kejadian peritonitis pada pasien continuous ambulatory peritoneal dialysis: Identifikasi mikroorganisme dan sensitifitas antibiotik (Thesis). Denpasar: Udayana University; 2010.

6. Lobo JVD, Villar KR, Andrade Junior MP, et al. Predictor factors of peritoneal dialysis-related peritonitis. J Bras Nefrol. 2010;32(2):15664. DOI: 10.1590/S0101-28002010000200004.

7. Nessim SJ, Bargman JM, Austin PC, et al. Impact of age on peritonitis risk in peritoneal dialysis patients: An era effect. Clin J Am Soc Nephrol. 2009;4(1):135-41. DOI: 10.2215/CJN.02060508.

8. Sirivongs D, Pongskul C, Keobounma T, et al. Risk factors of first peritonitis episode in Thai CAPD patients. J Med Assoc Thai. 2006;89 (Suppl 2): S138-45.

9. Gan HC, Lee EJ, Tay MM, et al. A study on early onset peritonitis in CAPD patients. Singapore Med J. 2003;44(3):138-40. 
10. Rochmah W. Diabetes melitus pada usia lanjut. In: Sudoyo AW et al., editors. Buku ajar ilmu penyakit dalam. 5th Ed. Jakarta: Internal Publishing; 2009:1967-72.

11. Waspadji S. Komplikasi kronik diabetes: Mekanisme terjadinya, diagnosis dan strategi pengelolaan. In: Sudoyo AW et al., editors. Buku ajar ilmu penyakit dalam. 5th Ed. Jakarta: Internal Publishing; 2009:1922-9.

12. Sarma SK, Chaurasia RK, Sijapati MJ, et al. Peritonitis in continous ambulatory peritoneal dialysis. JNMA $J$ Nepal Med Assoc. 2010;49(178):104-7. 